\title{
Electromagnetic characteristics of biosilica from rice husk
}

\author{
Vladimir Buz'ko ${ }^{1,2^{*}}$, Igor Shamray ${ }^{2}$, Alexander Goryachko ${ }^{1,2}$, Sergei Udodov ${ }^{1}$, and Anatoly \\ Abashin $^{1}$ \\ ${ }^{1}$ Kuban State Technological University, 350075, Krasnodar, Russia \\ ${ }^{2}$ Kuban State University, 350040, Krasnodar, Russia
}

\begin{abstract}
Rice husk, being a widely available natural plant renewable agricultural resource, can be transformed into effective reinforcing fillers of special concrete and gypsum building materials. The samples of silica from rice husks were synthesized by thermal oxidative pyrolysis and their electromagnetic and microstructural characteristics were investigated. It was found that the rice husk itself is practically EM-wave transparent material in the frequency range of $0.1-7 \mathrm{GHz}$, while the products of its thermal oxidative pyrolysis have different microwave absorbing properties, depending on the amount of oxidizing agent used. The X-ray powder diffraction data showed the predominant presence of amorphous silica in the samples of rice husk ash with a small amount of $\alpha$-quartz, $\alpha$-cristobalite and $\alpha$-tridymite. At a pyrolysis reaction temperature of rice husk of about $560 \pm 20^{\circ} \mathrm{C}$, the resulting product, in addition to amorphous silica and crystalline phases of silicon dioxide, contains traces of graphite particles, which leads to a sharp increase in dielectric characteristics and effective microwave absorption. When the temperature of the pyrolysis reaction of rice husk rises above $700^{\circ} \mathrm{C}$ the EM-wave absorption of such materials decreases. Thus, on the basis of the experiments carried out, the optimal ratios of rice husk and the used oxidizer of ammonium nitrate were revealed to obtain environmentally friendly ecological low-cost powder nanostructured biosilica additives for concrete and gypsum building compositions with increased effective radio absorption in the frequency range of the electromagnetic field above $1 \mathrm{GHz}$.
\end{abstract}

\section{Introduction}

Rice husk (RH) is agricultural waste and contained up about $20 \%$ of the mass of rice produced and is wide spread natural plant raw material for the production of amorphous silica $[1,2]$. The principal components of rice hulls are cellulose, hemicellulose, lignin and biogenic silicon dioxide [1,3]. It is known that under certain controlled combustion conditions of rice hulls, the main product is amorphous silica with high reactivity used for the production of concrete [4]. Amorphous silica derived from rice husk is a raw material for ceramic production [5], composite materials [6] and component of special concretes [7,

* Corresponding author: Buzkonmr@mail.ru 
8]. Biogenic silica from rice husks in the ash composition is from 92 to $95 \%$ [9] and is an amorphous modification of silicon dioxide, which is synthesized by plants in their vegetative parts and is associated with organelles and plant parts [2]. Rice husk silica is used abroad as an additive to create electromagnetic wave (EM) absorbing materials; however, practically nothing is known about the electromagnetic properties of rice husk silica samples obtained under various regimes of oxidative pyrolysis. This article presents the results of studies on the oxidation pyrolysis preparation of amorphous silica from rice husks with a high content of silicon dioxide and the investigation of its electromagnetic, microstructural and crystal phase characteristics for purpose of perspective using as filler for concrete and gypsum building compositions with regulated electromagnetic properties.

The objects of study were samples of rice husk ash (rice plant growing place Krasnodar Territory, Abinsky District), obtained by oxidative pyrolysis with various amounts of ammonium nitrate used as a cheap available solid oxidizer with a high positive oxygen balance, completely decomposing during heat treatment into gaseous products.

\section{Methods}

Air-dry rice husk weighed on an Ohaus Adventurer AR2140 analytical electronic balance (USA) and in the required various quantities was mixed with finely ground powder of ammonium nitrate $\mathrm{NH}_{4} \mathrm{NO}_{3}$ (chemically pure, Russian Federation). The resulting mixture was transferred into a $240 \mathrm{ml}$ porcelain crucible and placed on an electric stove IKA C-Mag HS7 (Germany). The mixture was heated at a speed of $20^{\circ} \mathrm{C} /$ minute. Upon reaching a temperature of about $180^{\circ} \mathrm{C}$, the decomposition of organic components of rice husks began to be observed, and upon reaching $315^{\circ} \mathrm{C}$, an intensive decomposition of ammonium nitrate took place with the formation of oxidizing nitrous gases, which led to a rapid burnout of organic components of rice husks with flame temperature increasing. After that, the crucible with ash was heated to a temperature of $500^{\circ} \mathrm{C}$ and kept there for 30 minutes. According to data $[3,11,12]$ at a temperature of $500^{\circ} \mathrm{C}$ in an air atmosphere, almost complete burnout of organic components of rice husks is observed. After that, the crucible with a sample of rice husk ash was cooled in air to room temperature and a comprehensive study of the properties of the obtained biosilica powder was performed.

Micrographs of rice husk ash powder samples were obtained with a scanning electron microscope Zeiss EVO HD15 (Germany) with X-ray energy dispersive microanalyzer unit for qualitative elemental composition of the rice husk ash samples. Laser particle size analysis (DLS) of rice husk ash powder samples was performed using a laser particle size analyzer Analysette 22 (Germany) in isopropyl alcohol using a liquid dispergation unit. To plot the graph of the distribution of silica particles by size, we used averaging over the results of five measurements.

X-ray diffraction (XRD) powder analysis of rice husk ash samples was carried out using Shimadzu XRD-7000 X-ray diffractometer (Japan). The identification of diffraction reflections and the search for crystalline phases in the samples were carried out using a computer program Profex 4.0.0.

The combustion temperature of the rice husk- $\mathrm{NH}_{4} \mathrm{NO}_{3}$ reaction mixture in oxidative pyrolysis process was measured with a digital thermometer UT303D (China) by means of averaging over the results of three independant measurements.

The bulk dry density of rice husk ash samples was determined by the pycnometric method. Specific surface area $S_{s p}\left(\mathrm{~m}^{2} / \mathrm{g}\right)$ values for rice husk ash samples in approximation of non-bonded isolated particles were calculated using the following equation:

$$
S_{y d}=\frac{6000}{\mathrm{D}_{\mathrm{p}} \cdot \rho}
$$


where $D_{p}$ - average weighted nanoparticle size from electron microscopy data, $\rho-$ crystallographic density of silica $\left(\sim 2,2 \mathrm{~g} / \mathrm{cm}^{3}\right)[13]$.

The electromagnetic characteristics of rice husk ash samples were investigated by vector network analysis using the Deepace KC901V device (China) in a $10 \mathrm{~cm}$ HP-11566A coaxial transmission airline probe (USA) by the standard way in the form of a composite $50 \%$ (weight) in paraffin in the form of a pressed toroid with dimensions $4 \times 7 \mathrm{~mm}$ and 4.5 $\mathrm{mm}$ thickness. The choice of the concentration of the investigated silica filler samples and paraffin as a matrix is due to the convenience of comparison with the known data on the previously investigated different types microwave absorbing fillers. Calculation of the electromagnetic characteristics of the samples from the measured scattering parameters $\mathrm{S}_{11}$ and $\mathrm{S}_{21}$ were carried out by the Nicolson-Ross-Weir method [14].

\section{Results}

The calculated yield of rice husk ash (RHA) depending on the ratio of the used ammonium nitrate and rice husk is shown in Figure 1a. It can be seen that with the increased of ammonium nitrate in the reaction mixture, the yield of ash decreased and reaches $20.4 \%$. The main reason is oxidative combustion of carbon-containing compounds and residues.
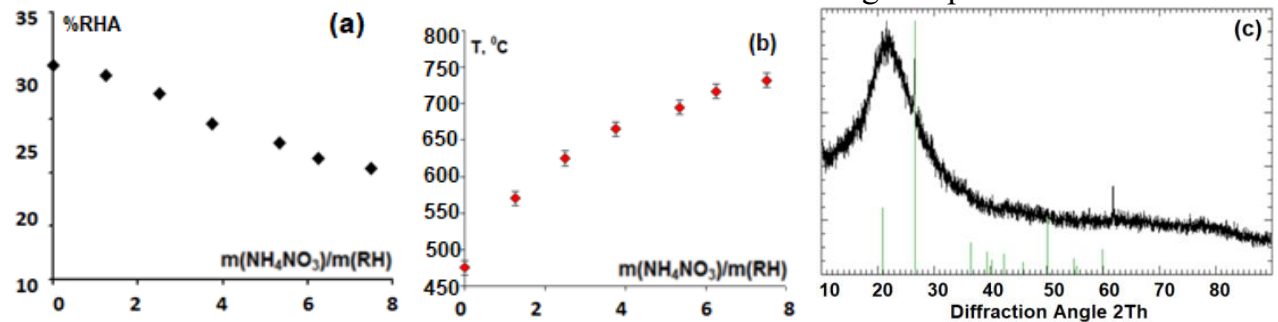

Fig. 1. Calculated yield of RHA (a) and combustion temperature (b) vs $\mathrm{m}\left(\mathrm{NH}_{4} \mathrm{NO}_{3}\right) / \mathrm{m}(\mathrm{RH})$ ratio; XRD of RHA $\left(\mathrm{m}\left(\mathrm{NH}_{4} \mathrm{NO}_{3}\right) / \mathrm{m}(\mathrm{RH})=2.5\right)$ with quartz reference data (c)

Combustion temperature of the reaction mixture $\mathrm{RH}_{-} \mathrm{NH}_{4} \mathrm{NO}_{3}$ at different ratio of $\mathrm{RH}$ and oxidant is shown in Figure 1b. The XRD data of silica sample prepared at $\mathrm{m}\left(\mathrm{NH}_{4} \mathrm{NO}_{3}\right) / \mathrm{m}(\mathrm{RH})=1.25$ ratio are shown in Figure 1c.

The DLS data for samples of RHA sample with different ratio $\mathrm{m}\left(\mathrm{NH}_{4} \mathrm{NO}_{3}\right) / \mathrm{m}(\mathrm{RH})$ are shown in figure 2. Processing of electron microscopy data using the Image $\mathrm{J}$ program to construct the structure of nanoparticles in size and calculate the average diameter of nanoparticles in the studied biosilica samples (figure 2).
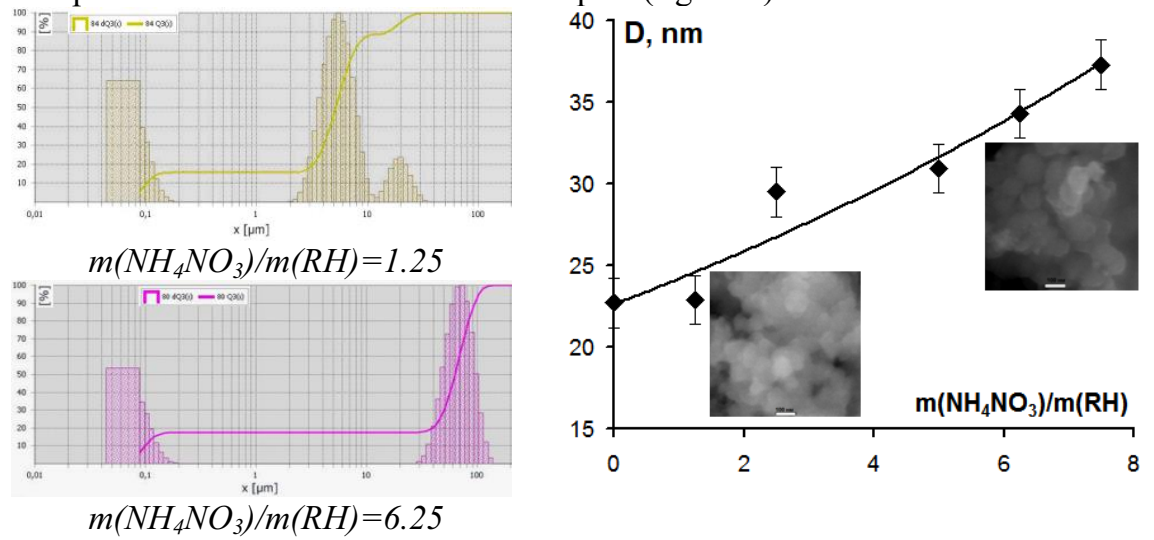

Fig. 2. DLS data $(a, b)$ and mean size of nanoparticles (c) of RHA sample with different $m\left(\mathrm{NH}_{4} \mathrm{NO}_{3}\right) / m(\mathrm{RH})$ ratio 
The electromagnetic properties of RHA sample with different ratio $\mathrm{m}\left(\mathrm{NH}_{4} \mathrm{NO}_{3}\right) / \mathrm{m}(\mathrm{RH})$ are shown in figure 3.

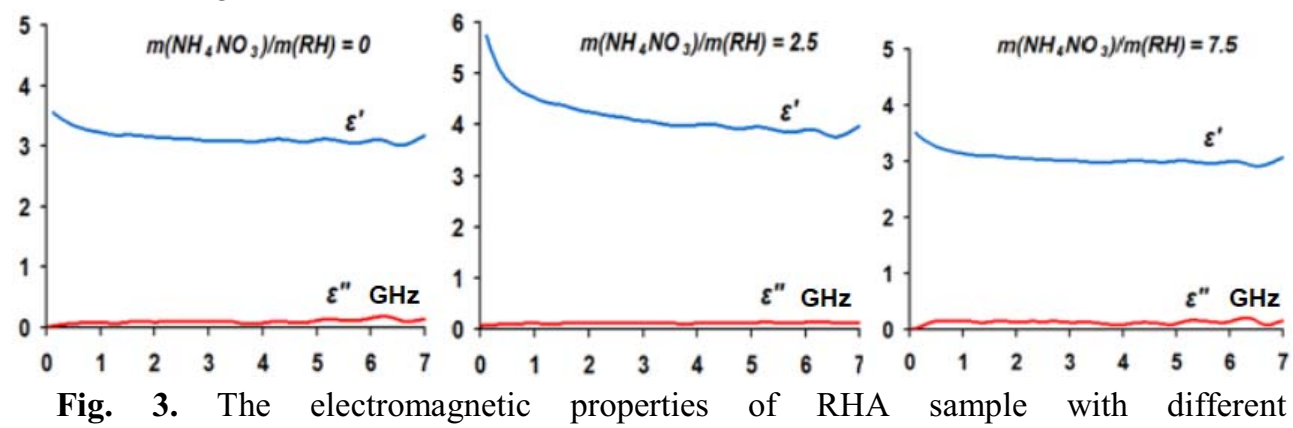
$m\left(\mathrm{NH}_{4} \mathrm{NO}_{3}\right) / m(\mathrm{RH})$ ratio.

\section{Discussion}

According to the data of [15], the interaction of ammonium nitrate with carbon materials upon heating can be expressed by the following chemical equation:

$$
\mathrm{NH}_{4} \mathrm{NO}_{3}+0,5 \mathrm{C} \rightarrow \mathrm{N}_{2} \uparrow+2 \mathrm{H}_{2} \mathrm{O}+0.5 \mathrm{CO}_{2} \uparrow
$$

The heat effect of this exothermic oxidative reaction is, depending on the type of carbon raw material, varied from 3,5 to $3,8 \mathrm{~kJ} / \mathrm{kg}$ [15]. Under our conditions, the addition of ammonium nitrate as an oxidizing agent led to a pronounced increase in the heat effect of the pyrolysis reaction of rice husks. So, when using the ratio of $\mathrm{NH}_{4} \mathrm{NO}_{3} / \mathrm{RH}$ equal to 5.5/1, the combustion temperature of the reaction mixture, measured with a UT303D digital thermometer, reached $710^{\circ} \mathrm{C}$. Such high reaction temperatures should promote the effective burnout of organic components of rice husks and can lead to both the transformation of the crystal chemical phases of $\mathrm{SiO}_{2}$ and the sintering of the resulting particles.

A wide complex peak in prepared RHA powder diffraction patterns in the range of reflection angles $2 \theta$ from 15 to $40^{\circ}$ clear indicates the amorphousness of the obtained silica. According to the data of powder X-ray diffraction analysis, the prepared samples of amorphous silica also contain $\alpha$-tridymite, $\alpha$-cristobalite, $\alpha$-quartz, graphite, and, probably, there are traces of $\alpha-\mathrm{Si}_{3} \mathrm{~N}_{4}$ and $\mathrm{SiC}(3 \mathrm{C})$.

Laser particle analysis of the prepared silica samples (Figure 2) showed that they are nanostructured micropowders. It can be concluded that the use of an excess of ammonium nitrate for thermal oxidation of rice husks leads to an increase in the size of nanoparticles and a noticeable sintering of agglomerates of microparticles of silica. According to SEM data, the obtained silica samples consist of aggregates of fused nanoparticles. The dependence of the weighted average diameter of nanoparticles in the studied samples shows a systematic increase in the size of silica nanoparticles with increasing excess of $\mathrm{NH}_{4} \mathrm{NO}_{3}$. Also, with an increase in the $m\left(N_{4} \mathrm{NO}_{3}\right) / m(\mathrm{RH})$ ratio, the calculated specific surface area for silica samples from rice husks decreases from 130 to $78 \mathrm{~m}^{2} / \mathrm{g}$ due to the intense sintering of nanoparticles and their aggregates under the action of high temperatures during the oxidative thermolysis reaction. Nevertheless, the dependence of the measured bulk density of rice husk ash samples shows changes from 362 to $419 \mathrm{~kg} / \mathrm{m}^{3}$ with a maximum at $m\left(\mathrm{NH}_{4} \mathrm{NO}_{3}\right) / m(\mathrm{RH})=3.75$.

Measurements of electrical conductivity at direct current showed a sharp increase in DC electrical conductivity for silica samples with the ratios $m\left(N_{4} \mathrm{NO}_{3}\right) / m(R H)$ equal 1.25 и 2.5. We assume, taking into account the data of X-ray spectral energy dispersive analysis, that a high content of residual carbon of about $1.6 \%$ (wt.) in the form of graphite nanoparticles, according to the available data of powder XRD structural analysis, leads to a significant observed increase in the dielectric constant and dielectric loss tangent for a 
biosilica sample with the ratio $m\left(N_{4} \mathrm{NO}_{3}\right) / m(\mathrm{RH})=2.5$ in comparison with other samples of the obtained silica.

The studied samples of rice husk and silica from it showed the absence of magnetic properties and are purely dielectric materials. For dry rice husk, the measured average values of dielectric constant and dielectric loss tangent in the range of $0.1-7 \mathrm{GHz}$ are $2.2 \pm$ 0.2 and $0.09 \pm 0.02$, which makes it possible to consider it as a microwave-transparent material. The values of dielectric constant and dielectric loss tangent in the range of 0.1-7 $\mathrm{GHz}$ for a sample of biosilica from rice husk obtained by thermolysis without using $\mathrm{NH}_{4} \mathrm{NO}_{3}$ as an oxidizing agent are $3.14 \pm 0.10$ и $0.03 \pm 0.01$ respectively. With the optimal ratio $m\left(\mathrm{NH}_{4} \mathrm{NO}_{3}\right) / m(\mathrm{RH})=2.5$, the dielectric constant and dielectric loss tangent of the composite are $4.19 \pm 0.37$ and $0.12 \pm 0.02$, respectively.

The obtained values of dielectric constant and dielectric loss tangent for the composites derived from biogenic silica sample with the ratio $m\left(N_{4} N_{3}\right) / m(R H)=2.5$ allow it to be used as an environmentally friendly low-cost microwave absorbing reinforcing filler for lightweight concrete compositions to absorb electromagnetic radiation with frequencies above $2 \mathrm{GHz}$, agreeing well with data [16]. As a microwave absorbing filler, produced by carbon-containing amorphous silica from rice hulls, it is inferior to previously studied domestic magnetic radio-absorbing materials such as magnetic microspheres [17], Fe-Si-Al alloy powder [18] or ferrites of spinel series [19,20], however, it is an easily produced low cost ecological microwave dielectric absorbing material. It is important to note that the microwave-absorbing nanostructured amorphous biosilica samples obtained by us was prepared by a simple low-tech method from cheap biorenewable natural raw materials, such as rice husk.

\section{Conclusions}

Thus, by pyrolysis treatment of rice husk with $\mathrm{NH}_{4} \mathrm{NO}_{3}$, nanostructured amorphous silica powders were obtained, in which, according to powder X-ray diffraction analysis, in addition to amorphous quartz a $\alpha$-tridymite, $\alpha$-cristobalite, $\alpha$-quartz, and graphite are present in much smaller amounts. The presence of impurities of the highly dielectric electrically conductive phase of graphite in the samples of silica obtained with the ratio $m\left(N_{4} N O_{3}\right) / m(R H)=1.25$ and 2.5 , leads to a noticeable increase in dielectric constant and dielectric loss tangent in comparison with other samples of the obtained silica from thermal destructed rice husk. The amorphous silica from rice husk with increased dielectric characteristics obtained at the optimal ratio of the oxidant $\mathrm{NH}_{4} \mathrm{NO}_{3}$ can be used as a lowcost strengthening nanostructured micropowder dielectric microwave absorbing filler for concrete and gypsum compositions.

\section{Acknowledgements}

The research was partly carried out with the financial support of the Kuban Science Foundation and the Kuban State Technological University in the framework of the scientific project № MFI-P-20.1/9 "Development and research of building and structural materials with special electromagnetic properties".

\section{References}

1. K. Ajay, M. Kalyani, K. Devendra, P. Om, International J. of Emerging Technology and Advanced Engineering 2, 86-90 (2012)

2. Shcherbakova T.P., Vaseneva I.N. Theor. Found. Chem. Eng. 54. 297-303 (2020)

3. K. G. Mansaray, A. E. Ghaly. Energy Sources 20. 653-663 (1998) 
4. P.K. Mehta "Siliceous ashes and hydraulic cements prepared therefrom" U.S. Patent 4,105,459 (1978).

5. S.S. Hossain, P.K. Roy. J. Asian Ceram. Soc. 6, 289-298 (2018)

6. S. Mohajerani, C. Zamani, A. Ataie. J. Ultrafine Grained Nanostruct. Mater. 52, 149153 (2019)

7. N. Piladaeng, N. Angkawisittpan, S. Homwuttiwong. Meas. Sci. Rev. 16, 14-20 (2016)

8. R.M. Ferraro, A. Nanni, R.K. Vempati, F. Matta. J. Mater. Civ. Eng. 22, 1078-1083 (2010)

9. H. Kaur, G. Deep, V. Chawla. Progress in Electromagnetics Research, 43, 165-173 (2015)

10. I.N. Sudiana, S. Mitsudo, M.Z. Firihu, La Aba, L.O. Ngkoimani, M.W. Arsana, H. Aripin. AIP Conf. Proc. 1801, 040003 (2017)

11. K.G. Mansaray, A.E. Ghaly. Energy Sources 21, 899-911 (1999)

12. S. Arora, M. Kumar, G.P. Dubey. J. Energy Inst. 82, 138-143 (2009)

13. Haynes William M., ed. CRC Handbook of Chemistry and Physics (92nd ed.) (Boca Raton, FL: CRC Press. 2011).

14. E.J. Rothwell, J.L. Frasch, S.M. Ellison, Chahal P., Ouedraogo R.O. Progress In Electromagnetics Research. 157, 31-47 (2016)

15. Y. Izato, A. Miyake, S. Date. Propellants Explos. Pyrotech. 35, 1-7 (2010)

16. Z. Zulpadrianto, Y. Yohandri, A. Putra. IOP Conf. Series: Materials Science and Engineering 335, 012002 (2018)

17. S.A. Vyzulin, V.Y. Buz'ko, D.A. Kalikintseva, A.I. Goryachko, L.I. Sarin, O.A. Kolantsov, N.E. Syr'ev. J. Phys. Conf. Ser. 1389, 012161 (2019)

18. A.I. Goryachko, S.N. Ivanin, V.Yu. Buz'ko. J. Phys. Conf. Ser. 969, 012019 (2020)

19. A.I. Goryachko, S.N. Ivanin, V.Yu. Buz'ko. Condensed Matter and Interphases. 22, 446-452 (2020)

20. V.Yu. Buz'ko, I.I. Shamrai, M.Yu. Ryabova, G.V. Kireeva, A.I. Goryachko. Inorg. Mater. 57, 38-43 (2021) 